\title{
Research on Functionality Sports Nutrition and Health Food Security Issues Based on Circulation
}

\author{
Jiangjing $\mathrm{Du}^{*}$
}

Mianyang Normal University, P.R. China

\begin{abstract}
With the continuous improvement of people's living standards in recent years, after The 2008 Beijing Olympic Games and In august 2009 the State Council promulgated the "Regulations of national fitness", nationwide fitness programming in China increasingly active, and more and more groups participate in physical exercise. Thus sports health food demand is increasing year by year. But facing wide variety of health foods on the market and wall-to-wall advertising, people often don't know how to choice sports nutrition and health food. Safety of health foods has attracted the attention of governments and internation alorganizations highly. So strengthening the health management of food hygiene is an important topic on the health aspects of food safety in China.
\end{abstract}

Keywords: Circulation, sports nutrition food, health food, food safety.

\section{INTRODUCTION}

In today's world, with the continuous improvement of the economic development and material life, nutrition, health, quality and security of food have become the focus of increasing concern to consumers. The organic food, green food, health food, dietary supplements, food and nutrition supplements, special nutritional food, functional food, special medical food, sports nutrition of various countries, have become a new growth point of food industry in recent years. The current global health food accounts for $5 \%$ of total food sales, amounted to billions of dollars, and it grows fast every year. USA sales of health food products currently are billions of dollars [1]. Japanese healthy food sales for a few one hundred billion yen in recent years and there are more than 3000 kinds of health food. There are more than 2000 kinds of health food in Europe, and sales to an annual rate of $17 \%$. Chinese health food in 2010 reached 100 billion yuan, and will reach to 100 billion yuan. From the development trend, living standards improve, people will inevitably focus on living and quality of life, and to the health of the consumer product transfer, and thus, spending money on health is inevitable. United Nations Industrial Programmer noted that the two sunrise industries in the 21 st century are electronicbased information technology industry and life sciences development-based health industry. And health care industry and the pharmaceutical industry it is the most potential for the development of the life sciences industry $[2,3]$.

After the 2008 Beijing Olympic Games, the central government puts forwards to achieve the competitive sports and mass sport conformity development. August 2009, the State Council promulgated the "National Fitness Regulations". Future government authorities in the provision of public goods and services will also sport a great effort, to ensure people's basic needs physical exercise. In addition there is still a lot of diversification, personalized sports demand due to the different income levels caused. In this context [4], China's national fitness campaign increasingly active groups in physical exercise, more and more people's health awareness gradually increased, the demand for health food has also increased. But facing wide variety of health foods on the market and wall-to-wall advertising, people often don't know how to choice sports nutrition and health food. Safety of health foods has attracted the attention of governments and internation alorganizations highly. So strengthening the health management of food hygiene is an important topic on the health aspects of food safety in China.

Health food safety is a major health and social stability of the peoplesand has become the focus of the world's governments and the public increasingly concerned. Today China's rapid economic development and rising living standards, we should actively establish sound health food safety control security system, strengthening government health food safety supervision, the establishment of health food safety control detection and early warning systems to ensure that our people quality and safety of health food, narrowing the gap with the world's advanced countries in terms of food safety, health, and promote the improvement of China's overall level of health food industry has a very important practical significance $[5,6]$.

\section{THE CATEGORY OF SPORT AND HEALTHY FOOD}

According to the promulgated sports nutrition industry standards and national standards, and the formats of sports nutrition food industry developed, sports nutrition can be divided into energy supplements food, protein supplements food, energy control food [7]. 
Energy supplements food provides for movement of energy the body needs to improve movement of energy supply during exercise, thus ensuring the movement and inspire potential and performance. Energy supplements food includes a variety of solid energy supplements, sports drinks and powdered supplement food. Solid energy supplements in various energy bars to represent its portable, cheap, easy to use, has a higher energy content than ordinary food, etc., is the most important energy supplements a class of products. Sports drinks contain some sugar, with beneficial vitamins and electrolytes during exercise to restore the balance of the characteristics of the liquid form also help the body absorb more $[8,9]$. Sports drinks for a wide range of people can be used as an ordinary consumer product from non-sports people, therefore, holds the largest share of the sports drink throughout the sports nutrition foods. Energy can be brewed into a powdered food supplement that can be described by a simple pickle athletes provide sufficient energy, a representative of a variety of carbohydrate powder.

Protein supplements food's main function is to promote a balance of protein metabolism and promote muscle growth by promoting protein synthesis. The main products are protein powder, creative products, etc. Protein powder principally through the provision of some high quality gas-based acid or protein to promote muscle growth, according to different sources of protein can be divided into egg protein, casein, soy protein and whey protein, where the highest nutritional value of whey protein extracted from milk, contains eight kinds of amino acids essential human species. Creation existences and the human body can be synthesized by the body's own. But in the case of a large amount of exercise, often requires the use of creation sports nutrition supplement. Creation is a substance from arginine, glycine and methionine, three amino acid syntheses. There are water creation and grape acid compound creative categories.

Energy control food primarily by changing the metabolism of certain substances in the body so as to change the role of targeted physical exercise capacity. Its representative products for sports nutrition foods contain carnitine, in the case of a large amount of exercise, taking carnitine can alter fat metabolism and strengthen the supply of oxygen to improve exercise capacity and fatigue resistance.

\section{DEVELOPMENT OF CHINA'S HEALTH FOOD INDUSTRY}

Someone named the past two decade development of Chinese health care market, according to a representative of a certain period of health product. From the late 1980s to the present China's basic health care market is divided into four time: In the late 1980s the sun god times, the mid-90's SanZhu times, the Hearts K times of late 1990s, and Melatonin times in the early 21 st century. From that we can find a phenomenon that the development trends of health food products is wavy trend, that's to say a climax followed by a trough, and for customers the next consuming concept is more mature that previous, showing that the consumer is ]becoming more mature and rational ideas [10-13].

From our approved the listing of thousands of health food varieties, China's health food products have the following features. (a) The widely used of natural raw materials. More traditional theory of health-oriented products based on the design, the application of traditional food, animals and plants and other natural substances as the main raw material.

(b) Health care function is concentrated. The current development of health food, about two-thirds of product features concentrated in immune regulation, anti-fatigue and regulation of cholesterol and other aspects

(c) Compared with the traditional food the distance in sense of the form is large. Common forms are capsules, tablets.

(4) Products contain different technological. Because of the long development cycle of health food, production companies' also quick success, ignoring the innovation and product development process, results in the current health food mostly not high tech.

(d) Products' origin is concentrated. Prior to the approval of the production of health products to Beijing, Guangdong region represented occupy the entire country to declare the number of health food 54\%. According to the order of the declaration quantity the top five are: Beijing, Guangdong, Shandong, Jiangsu, and Shanghai.

(e) The number of domestic health care products accounted for the majority。 Imported health food accounted for only $20 \%$ the number of domestic health food, but they occupy more than $60 \%$ of the market.

Although Chinese health food market less than in previous years some confusion, but there are still many problems. The most typical is "one little", "too many", "three low" phenomenon: The vast majority of small-scale enterprises, many enterprises, product repetition, low-tech products, low management level, low development capacity.

To sum up, the current problems in the health food industry, mainly as follows:

1. Small-scale, low technology investment, anti-risk ability.

2. Products repeat, low tech, low development capabilities.

3. Product life cycle is short, usually only 3-4 years.

4. Proliferation of counterfeit health products

5. False hype cause consumer health care products to reduce the level of trust.

6. Regulations is not perfect, the management model is still not mature enough.

7. Consumers immature, passive consumption, mindless consumption, deformities consumption is serious.

\section{FOOD SAFETY ISSUES}

\subsection{Raw Materials}

Due to the extensive use of Chinese medicine health food extract raw materials, and in our country planting herbs is the same with the planting plant products, heavily using of pesticides, and fertilizers. Drug residues, organic pollutants, 
environmental pollutants are difficult to avoid. Currently the world there are 35,000 kinds of medicinal plants used in our country, about more than 7000 kinds of Chinese medicine, most of which are planted by human. Inconsistent quality, high pesticide residues, harmful elements such as excessive quality and safety issues directly affect the quality and safety of health food.

In 2001 the government of California found that originating in China more than 110 kinds of Chinese medicine and Chinese medicine heavy metal content in excess of the California drinking water standards, which is a clear signal. Some herbal cultivation period is very long, and pollution problem is even more serious. In 2004 Hong Kong Department of Health found that two kinds of ginseng powder hexachlorobenzene, 666, PCNB exceeded. Throughout our 12 categories of functional health food substances, mostly come from the cultivation of crop products, such as mushroom, tea, ganoderma, ginseng, pollen, Tianma, yam, kiwi fruit, vegetables (garlic, radish), soybeans, sugarcane, tomato, licorice, corn, beans, etc. In the current food safety inspection report, Organophosphorus pesticides (Methamidophos etc.) in vegetables exceeded, the problem of DDVP, formaldehyde in mushroom, lead and pyrethroid pesticide contamination in tea, Grain containing mycotoxins (AFT and $\mathrm{FB}$ ), aquatic algae neomycin (MC), etc. are is still one of the major issues affecting the quality and safety of consumer health. Due to the different distribution factors, functional components extracted during intake, pollutant degradation during processing and destruction should be said with traditional food safety issues differ. But the main impact of the magnitude of the MRL, while the corresponding limit indicators, test methods, and to solve the health food of plant origin is still a source of pollution must be controlled GAP. Otherwise, our health food hygiene and safety issues difficult to be guaranteed.

On the premise of realizing the system function, user audit management, the client identity authentication, data storage, system log processing and access control are involved in the construction. The availability, integrity and reliability of the system can be ensured in the cloud computing file management.

There are a considerable number of foods derived from animal sources, livestock products, aquatic products in China health food, such as shellfish (oysters, etc.). Shrimp, fish (sharks, etc.), tortoises, turtles, marine animals (e.g. seals), honey, royal jelly, propose, sea cucumber, cattle, pigs, and some wild animals. From the current safety monitoring report of food of animal origin can be seen that honey, royal jelly antibiotics (tetracycline, chlortetracycline, etc.), aquatic harmful elements (mercury, arsenic, lead), sterilization drug residues, there may be paralysis, amnesia, neurotoxins and other shellfish. Animal bones are as raw biological calcium supplements, calcium-fortified foods and their toxic effects of heavy metal contamination. China's honey were found insecticidal squint exported to Germany, and found streptomycin squint exported to England. Marine health foods, especially fish offshore, such as shellfish, fish, seaweed, kelp, seaweed, $\mathrm{Pb}, \mathrm{As}, \mathrm{Hg}, \mathrm{Cd}$, almost all exceeded.

Some plants with different food source of health care, health food products of animal origin as a result of generally concentrates, dry powder form occur more frequently. In addition, the use of marine animal bones, shells, pearls raw materials to produce calcium health care products, $\mathrm{Hg}, \mathrm{Pb}$, $\mathrm{Cd}$, As deposited in the bones, causing pollution and heavy metal poisoning. In general, the quality of health care products of animal origin raw material safety culture is more need to pay attention to control.

\subsection{New Resources/New Processes/New Technology}

The safety of new food resources relate to the food in line with the basic requirements, which is newly researched, newly discovered, newly introduced, and no usage habits or only in individual areas in our country. The food produced by new resources is called new resources of food. Its safety should be strictly in accordance with the relevant provisions of the "new resource food hygiene management approach" audit. Such that high protein, good dietary fiber, calcium source of food: yeast protein, leaf protein, insect protein, algae protein can enter the food category after appropriate processing. More, front raise various vegetables, coconut, grain amaranth; blackcurrant, sea buckthorn, grape seed oil, jujube, etc. The newly developed internationally for health food in recent years: Policosannoe, comes from sugar cane wax, can reduce holesterol; CoraLCa, comes from Coral, its function is calcium supplements; Xylitol, comes from Canada birch juice, can lose weight and anti-tooth decay; LAmino acids, comes from watermelon juice before, now produced by synthetic, can expansion of blood vessels, improve memory, fatigue; Lycopene, comes from tomato before, now produced by synthetic, is a kind of strong antioxidant.

Of course, the United Nations Economic Cooperation Organization Development (OECD) in the 1990s made that if a new food or food ingredient is mixed with a food or ingredient is already present in substantially the same, in terms of safety, they are the same. This is the famous "principle of substantial equivalence". I think when making safety assessment of a new resource health food can also refer to this principle.

In the security field of new technologies, bear the brunt of transgenic technology is the development of health food raw materials safety issues. Internationally there is a lot of controversies: (1) Food nutritional quality change: the shift of nutrients and toxins, changes in bioavailability problems, nutritional balance, changes affecting food safety; (2) Potential toxicity of change in food: when GMO open one gene at the same time, inadvertently increase the content of some natural toxins, such as solanine in potatoes, cassava cyanide.

Potential allergens' or allergy protein's change in raw food of health products will enter a new plant with gene. For example, Brazil nut has allergy fibrinogen, if moves this gene to soy, Soy protein improves, but soy also has allergic.

Health food now uses some new technology, Such as nanotechnology, microencapsulation technology, chelation technology, significantly altering the bio-availability of the original number of nutritional supplements. If one company claims to have developed a nanoscale daidzein tablets, pro- 
polis health Po, Aloe Vera, vitamin, Ga tablets, when generally conventional doses, it will greatly increase the absorption to poison.

At present, the use of advanced biotechnology, such as the use of food fermentation industry, provides training for human protein, high nutrients and probiotics, when the productions of health food, industrial Safety bacteria also need attention. Health food industry producing bacteria strains pollution in the production and processing is also concern in the international food safety issues. Development and utilization of new food resources has also led to new emerging fungi. On the one hand the new strain of foreign production of health food has entered the Chinese market, and is currently used in the food industry of security control bacteria, from management to technical support are a lot of gaps exist. Even when a health food production strains considered safe in the long process of shipping may mutate, mutation of toxigenic species, leading to toxic metabolites of health food contamination. Such as the mid-1980s, the Institute of Microbiology of soy sauce production strains have been found to have four to generate AFT bacteria. Red yeast rice is a traditional Chinese health food fermentation bacteria, lower blood pressure, blood glucose and lipid lowering health functions, but now found some red yeast strains can produce toxic citrinin. In addition to red yeast, the fungus Aspergillus niger and other bacteria ferment sucrose, corn starch production of various oligosaccharides health food. Very similar to the black Aspergillus can produce kidney toxicity and carcinogenic metabolites. Bacillus subtilis natto Nattokinase can produce variants having strong hemolysis. Gray is streptomycin Streptomyces strains, thus producing bacterium health food may be contaminated streptomycin.

\subsection{Import Health Care Products}

Health food consumption and economic level of a country or region are closely related. With China's rapid economic development, further improve domestic living standards. All ages (such as elderly needs, young market, children's health products, women's health market, small capacity and health food) increase the demand for health food market. This must attract many international well-known health care products companies. They exquisite, merger, lease or direct import, to enter the Chinese market multiple forms, a large influx of foreign health care products. According to statistics, in 2000 the market for 302 kinds of imported health products, health care products imported in 2010 nearly 1000 kinds. Chinese mainland sells well only about 200 species, so this is actually foreign health care has occupied most of the health care market country.

At present, China's major foreign brands of health products Niuhaiersi, Kang Xin force, vitality, Golden Bear, a new life, etc. The main component of health care products imported concentrated in nutrients, such as unsaturated fatty acids, protein, vitamins, minerals, cellulose and the like. Also has access to animal and plant extracts, such as glucose oil, fish oil, etc. Products are mainly concentrated in the regulation of immune function, beauty, slimming, and antiaging, anti-fatigue, improve sleep. And they often become a series of products, Amway's Nutrilite plant protein family, and Canadian Fu Laixin import health series. These imports because of the quality of health care security towers must pay close attention.

Because the international health endless variety of different functions, security is not the same, except for some natural plant toxicity, contamination of animal organs, illegal drug uses have also been reported. Ocean health products harmful elements, pesticide residues in vegetable protein, shellfish and algae bio toxins health products, infant formula nitrite exceeded the detection of unknown GMO ingredients, etc. are also emerging microbial exceeded. The most sensational Chinese imports of health care products market, comes in September 2003 the Beijing Municipal Health Bureau issued a ban on the sale of imported health food Niuhaiersi announcement, was exposed as many as 61 varieties. Notices announced four major problems, all related to quality and safety.

On the other hand, as China increasingly expanding international trade of agricultural food, as raw herbal health products, edible agricultural products (including buckwheat, oats, whole grains, water, seafood, soy, corn, tea, milk, ginseng, etc.) import surge. China's imports of American ginseng, maple syrup, ice wine from Canada, USA. We import medicines from tropical South Asian countries. We extract from Japan, South Korea imported plants. And these care health safety and quality of raw materials in many examples of risks. For example, Imported from Ireland infant formula marching excessive nitrite, import of tea from Ceylon $\mathrm{Pb}$ value excessive, Imported from Thailand calcium health care products dry fish bone lead and cadmium exceeded.

\section{MATERIAL AND METHODS}

The existence of the above, there are kinds of health food safety issues. Facing those safety problems, what should we do?

Health care products companies should reshape health care image of integrity, restore consumer confidence, condemned counterfeit and illicit drugs add wrongdoing. Companies need to increase investment in science, and take the road of innovation with the development of modern science and technology with Chinese characteristics, excellent product from the treasure house of traditional Chinese medicine in our country.

Government regulatory responsibilities: (1) First, strengthen supervision, to change the past, "re-approval regulatory" situation. In addition to strict examination and approval according to the law (toxicological testing, functional testing, functional components inspection, stability testing, hygiene and quarantine), while regulators should strengthen the label, check the health indicators. Improve circulation daily supervision of health food is also very important. Random samples from the market, according to the requirements for approval when the system is checked, and the results should be regularly. Promptly announced in the media, business and non-conforming product punished. More importantly, should be on the technical aspects of health food safety. Functionality of key technologies should be strengthened. (2) Improve the relevant laws and regulations. As soon as the appropriate policies to improve the system and technical specifications, technical standards confor- 
mity assessment system, strengthen international exchanges, learn from foreign advanced management mode of health food.

Consumers need to strengthen self-protection awareness, positive rights to use legal weapons to strengthen the supervisory role of the media. Governments should also develop more specific legal provisions constrained enterprises, and increase efforts to punish, we must have strict rectification, but also have a long-term institution-building security arrangements and planning.

In short, the current development of China's health food industry is in a very critical period. Government approval and oversight of the two departments should strengthen cooperation and resolutely implement the State Council, the ten major initiatives to strengthen food security, together with businesses, consumers together to promote healthy Chinese health food industry forward.

\section{CONFLICT OF INTEREST}

The authors confirm that this article content has no conflicts of interest.

\section{ACKNOWLEDGEMENT}

This work is supported by the Key Project of Guangxi Social Sciences, China (No. gxsk201424), the Education Science fund of the Education Department of Guangxi, China (No. 2014JGA268), and Guangxi Office for Education Sciences Planning, China (No. 2013C108).

\section{REFERENCES}

[1] C. Menard, and G.K. Peter, "Organizational Issues in the Agrifood Sector: Toward a Comparative Approach," American Journal of Agriculture Economics, vol. 86, no.3, 2004.
[2] D. M. Lambert, K. T. McNamara, and M. I. Garrett, "Food Industry Investment Flows: Implications for Rural Development," The Review of Regional Studies, vol. 36, no. 2, pp.140-162, 2006.

[3] D. Pick, "Product Differentiation and Asymmetric Information in Agricultural and Food Market: Defining the Role for Government: Discussion," American Journal of Agriculture Economics, vol. 85, no.3, pp.742-743, 2003.

[4] G. Hendrikse, and J. Bijman, "Ownership Structure in Agrifood Chains: The Marketing Cooperative," American Journal of Agriculture Economics, vol. 84, no.1, pp.104-119, 2002.

[5] C.M. Hasler, and A.C. Brown, "Position of the American Dietetic Association: Functional foods," Journal of the American Dietetic Association, vol. 104, no.5, pp.814-826, 2004.

[6] K. Menrad, "Market and marketing of functional food in Europe," Journal of food engineering, vol. 56, no.2-3, pp.181-188, 2003.

[7] M. Carriquiry, and B. A. Babcock, "Reputations,Market Structure, and the Choice of Quality Assurance Systems in the Food Industry," American Journal of Agriculture Economics, vol. 89, no.1, pp.12-23, 2007.

[8] P. Coppens M.F. da Silva, and S. Pettman, "European regulations on nutraceuticals, dietary supplements and functional foods: A framework based on safety," Toxicology, vol. 221, no.1,pp.59-74, 2006.

[9] P. J. Jonesa, and S. Jew, "Functional food development: concept to reality," Trends in Food Science \& Technology, vol. 18, no.7, pp.387-390, 2007.

[10] R. Ryder and A. Fearne, "Procurement best practice in the food industry: supplier clustering as a source of strategic competitive advantage," Supply Chain Management: An International Journal Supply Chain Management: An International Journal, vol.8, no.1, 2003.

[11] S. Henson, and G. Holt, "Exploring Incentives for the Adoption of Food Safety Controls: HACCP Implementation in the U.K. Dairy Sector," Applied Economic Perspectives and Policy, vol. 22, no.2, pp.407-420, 2000.

[12] K. S. Sara, "The Persistence of Profitability among Firms in the Food Economy," American Journal of Agriculture Economics, vol. 87, no.1, pp.103-115, 2005.

[13] W. Verbeke, "Consumer acceptance of functional foods: sociodemographic, cognitive and attitudinal determinants," Food Quality and Preference, vol. 16, no.1, pp. 45-57, 2005.

\author{
Received: June 10, 2015 \\ Revised: July 29, 2015 \\ Accepted: August 15, 2015 \\ (C) Jiangjing Du; Licensee Bentham Open.
}

This is an open access article licensed under the terms of the (https://creativecommons.org/licenses/by/4.0/legalcode), which permits unrestricted, noncommercial use, distribution and reproduction in any medium, provided the work is properly cited. 